POLLACK PERIODICA

An International Journal for Engineering and Information Sciences

DOI: $10.1556 / 606.2017 .12 .1 .9$

Vol. 12, No. 1, pp. 107-122 (2017)

www.akademiai.com

\title{
HORIZONTAL SCRAPED SURFACE HEAT EXCHANGER - EXPERIMENTAL MEASUREMENTS AND NUMERICAL ANALYSIS
}

\author{
${ }^{1}$ Tibor VARGA, ${ }^{2}$ Gabor SZEPESI, ${ }^{3}$ Zoltán SIMÉNFALVI \\ Department of Chemical Machinery, Institute of Energy and Chemical Machinery \\ University of Miskolc, e-mail: ${ }^{1}$ vargat@motiva.sk, ${ }^{2}$ szepesi@uni-miskolc.hu, \\ ${ }^{3}$ simenfalvi@uni-miskolc.hu
}

Received 24 January 2016; accepted 30 August 2016

\begin{abstract}
This paper deal with the overall heat transfer process and confrontation of experimental measurements and their numerical solutions on simplified model, inside the horizontal scraped surface heat exchanger. The experimental measurements were done on two horizontal scraped surface heat exchangers connected in series. As a product was thermally treated water, heated by vapor in the first stage and cooled by cold water in the second stage. Applied mass flow of the product: $m=250,500,750,1000 \mathrm{kgh}^{-1}$ and rotary velocity of the shaft, scraper blades: $r p m=20,30,(45), 60,90 \mathrm{~min}^{-1}$. For numerical analyses the simplified model was used, with taking only the area between the heat transfer tube, and the shaft with an aim to compare the result to experimental measurements and validate the obtained overall heat exchange, as justify the simplification. As a results from experimental measurements were obtained the correlations for Nusselt number in a form of $N u=f\left(\operatorname{Re}, P r, \eta_{f} / \eta_{w}\right)$. Based on the confrontation of results, it can be stated that the level of simplification used at numerical solutions, gives still an acceptable accuracy of overall heat transfer values. From numerical simulations were obtained further results as the velocity, temperature fields, which were used to make certain adaptation on proposed construction and their examination by additional numerical simulations. All these acquired results lead to better understanding the overall process inside the horizontal scraped surface heat exchangers and the proposed construction of mutators can increase the efficiency of heat transfer process for many products in a real processing.
\end{abstract}

Keywords: Scraped surface heat exchanger, Velocity profile, Heat transfer coefficient, Turbulence, Computational fluid dynamics 


\section{Introduction}

Thermal processing of high viscous, non-Newtonian, sensitive products, as cheese, deboned meat, caramel, puddings, glues, dyes, etc. in chemical, food and consumption industry is managed by the usage of Scraped Surface Heat Exchangers (SSHE). Using other types of heat exchangers as shell and tube, plate etc., would be impossible because of high viscosity of processed product, the intensive formed layer of silt on heat transfer surface from starting of the operation immediately, the sensitive behavior of products etc. There are some disadvantages of SSHE as well, which should be mentioned, like: possibility of mechanical cleaning, maintenance, compactness, and duty changes after installation or economical (cost). Even of these disadvantages, their usage has a wide range of application, as the other types cannot fulfill the operational, process requirements.

The very first type of these SSHE was the stirred vessels for batch processes. Due to the request to increase the quantity of processed products and keep the quality of them still on a high level, were developed the continual scraped surface heat exchangers (rotational or axial execution). The main goal of these heat exchangers are to keep the heat transfer surface clean without unwished dust, silt layer of treated products and mix up it from the heat transfer wall into the main axial flow by means of scrapers and rectifiers. The layer would create a very high resistance against the heat transfer on the inner, product side of the heat transfer tube, wall.

Development of scraped surface heat exchangers are based on a wide range of experimental measurements on plant units, where the correlations for Nusselt number are obtained, generally in a form as follows

$$
N u=f\left(\operatorname{Re}, \operatorname{Pr}, \eta_{f} / \eta_{w}, D / d, L / D, \cdots\right),
$$

where $N u, R e, P r$ are the characteristic non dimensional variables; $\eta_{f}, \eta_{w}$ are the thermodynamic properties; and $D, d, L$ are the characteristic dimensions of SSHE.

These correlations allow calculating the heat transfer coefficient for inner-product or outer-cooling, heating side. Because of the wide range of products and their thermodynamic behaviors, like viscosity, sensitivity, which to be thermally processed, needs a wide range of construction types of scraped surface heat exchangers. This brings the development of votators, mutators (internal construction of SSHE, - which means the shaft and the scraper blades, rectifiers on it), where usually the correlations are referred for the inner side, as the outer, - shell side is quite explored including the heat transfer coefficients (using water vapor, some coolant etc.). In this case a small modification of internal construction comparing to the one from which the correlation could be used, would cause a high risk for sizing the new heat exchanger, as the assumption of the necessary geometrical, hydro-dynamical similarity is not fulfilled. Taking into account this matter, a huge amount of experimental measurements was done, and still should be provided for specific products, and requirements at its processing conditions. To reduce the costs and the time for experimental measurements (introduction a new construction of SSHE for specific product), and improve the internal constructions of scraped surface heat exchangers could use a Computational 
Fluid Dynamic (CFD) tools for numerical solutions (e.g. ANSYS CFX, Fluent). By these tools a wide range of constructions and process conditions can be checked without building up the real pilot plants and only for the best results the experimental plant, measurements shall be provided for final validation. The subject of presented paper is to introduce the results of the experimental measurement for the horizontal SSHE with one of the new internal mutator's construction and the results from its numerical simulation, including their comparison.

\section{Theoretical approach}

As it was mentioned, the first experiments were done by the stirred vessels for cooling, heating as for the crystallization. At the beginning of $20^{\text {th }}$ century Huggins F. E. [1] observed that using the scraper blades, causes higher efficiency of heat transfer. The difference was less notable for low viscous fluids as for the fluids, products with significant viscosity. In a case of crystallization, when crystallization occurred at the heat transfer wall the heat transfer coefficient value was estimated about $200-1000 \mathrm{Wm}^{-}$ ${ }^{2} \mathrm{~K}^{-1}$, while it occurred in a near area of the heat transfer wall, the heat transfer coefficient was reported about $1000-2000 \mathrm{Wm}^{-2} \mathrm{~K}^{-1}$. Lattinen G. A. [2] was working on the theoretical solution for the inner side of the heat transfer wall based on the heat conduction for the semi-infinite body. He presumed the cooling on the heat transfer wall by molecular transport until the product is not mixed with the main flow by scrapers. His correlation has the form:

$$
N u=\left(\frac{2}{\sqrt{\pi}}\right)\left(\operatorname{Re}_{r o t} \operatorname{Pr} Z\right)^{1 / 2}
$$

where $\operatorname{Re}_{r o t}, \operatorname{Pr}$ are the characteristic non dimensional variables; $Z$ is the number of blades used for scraping in section.

Harriott P. [3] has noted in his work that correlation (2) obtained by Lattinen G. A. [2] gives good approach for low and middle viscous products, while for high viscous those differ by more than $50 \%$ due to the bad mixing from near surface layer to the main stream. Another correlation obtained by Skelland A. H. P. [4] is in the form:

$$
N u=4.9\left(\frac{D v \rho}{\eta}\right)^{0.57} \operatorname{Pr}^{0.47}\left(\frac{D N}{v}\right)\left(\frac{D}{L}\right)^{0.37}
$$

where $\eta, \rho$ are the thermodynamic properties; $N$ is the rotating velocity of the shaft; and $v$ is the average axial velocity of treated product.

This correlation was built for inner side of the heat transfer wall in a case of crystallization. Furthermore, he investigated to get some correlations by dimensional analyses, where he assumed the following matters having the major influence of heat transfer processes: 
- thermal conductivity of treated product;

- the axial flow velocity through the SSHE;

- rotational speed and the diameter of the shaft;

- the diameter of heat transfer tube-wall;

- the thermodynamic properties of the product; and

- the length of the heat transfer tube.

Weisser H. [5] in his work investigated on the impact of flow character on the heat transfer and power input in SSHE. He noticed that flow is sustained by shear and pressure forces, which cause an energy dissipation and should be taken into the account by the total energy equation. Further, by better heat transfer between the main stream and layer close to the heat transfer wall, the overall heat transfer through the heat transfer wall will be higher into the product (processed fluid). Possible presence of back-mixing will decrease the driving power of the heat transfer. In general the tangential velocity component has a more significant effect as axial component. Usually there are following type of flow present inside the SSHE's: laminar flow (Couette flow), laminar flow with Taylor vortex, turbulent flow and turbulent flow with Taylor vortices, where the first two types are the most common flow types in SSHE's. Because of the back-mixing effect on a heat transfer, one of the possible modeling the temperature course is the model with plug flow and turbulent heat transfer coefficient (mixing coefficient). Assuming that the heat transfer coefficient, the temperature of the heat transfer wall and the turbulent - mixing coefficient are constant, it's possible to determine the axial temperature field in SSHE as follows:

$$
\begin{aligned}
& \rho v S c_{p} T-\lambda_{\text {turb }} S \frac{\partial T}{\partial z}=\rho v S c_{p}\left(T+\frac{\partial T}{\partial z}\right) d z \\
&-\lambda_{t u r b} S\left(\frac{\partial T}{\partial z}+\frac{\partial^{2} T}{\partial z^{2}}\right) d z+\alpha \pi D d z\left(T-T_{S}\right), \\
& \frac{\partial^{2} T}{\partial z^{2}}-\frac{\rho c_{p}}{\lambda_{\text {turb }}} v \frac{\partial T}{\partial z}+\frac{\alpha \pi D}{\lambda_{\text {turb }} S}\left(T_{S}-T\right)=0
\end{aligned}
$$

if $Z_{b}=z / L$, then

$$
\frac{\partial^{2} T}{\partial Z_{b}^{2}}-P e_{D} \frac{\partial T}{\partial z}+\operatorname{StPe}_{D}\left(T_{S}-T\right)=0
$$

Solving the last equation the axial temperature course can be obtained, where $P e_{D}=\nu L / D_{E}$ and $D_{E}$ are the diffusible mixing coefficient $D_{E}=\lambda_{t} / \rho c_{p}$; and $S t=A \alpha_{s} / m c_{p}$, further, $c_{p}$ is a thermodynamic property; $S$ is the characteristic dimension of SSHE; $T$, $T_{s}$ are temperatures ( $T_{s}$ is the wall temperature); $\alpha$ is the heat transfer coefficient; and 
$\lambda_{\text {turb }}$ is the turbulent heat conductivity. Based on his experiments, determined the mixing coefficients for different operational conditions.

Härröd M. [6], [7] investigated about the character and profile of flow, radial and axial mixing as the heat transfer in a wide range of process conditions with water and starch pastes. The investigation was done quite detailed about the transition between laminar and vortical flow, their effect on radial mixing and radial temperature differences.

Tero T. [8] in his dissertation thesis investigated with crystallization, especially with generation of crystals, their growth and their layer growth. Based on his investigation he reported a graph for heat transfer coefficient (inner and overall) and heat flow (specific heat flow) in dependence on flow speed for both. Pascual M. R. et al. [9] measured the flow and thermal filed in their experimental SSHE for crystallization, while Wilson S. K. et al. [10] for their own geometrical solution prepared a mathematical model for 3D flow through their heat exchanger.

Trommelen A. M. [11] in his work focused on character of flow, residence time, heat transfer and the necessary power for mixing. He studied the effect of flow how to reach the highest heat transfer coefficient and the best mixing of the treated product from the heat transfer wall to the main stream. He observed the necessary power for shaft rotation based on the shear stress of the high viscous product, fluid. Because of the unwished effect of the back-mixing on the heat transfer, he observed further the character of flow, the residence time and mixing the treated product with the main stream. For a case of Couette flow and Taylor vortices inside the annulus with rotating inner wall he noticed the critical Reynolds number as follow:

$$
\frac{N d(D-d) \rho}{4 \eta}=\left(\frac{\pi^{4}\left(0.5+\frac{d}{D-d}\right)}{0.0571\left(1-\frac{0.652(D-d)}{d}+0.00056\left(1-\frac{0.652(D-d)}{d}\right)^{-1}\right)}\right)^{\frac{1}{2}} .
$$

It should be mentioned that in most of the case the common process conditions are near to the change from one type of the flow to another.

Bongers M. M. P. [12] introduced a mathematical model of an ice cream freezer employing heat and mass transfer equations for freezer barrel as a series of well mixed stages, where he described the advantages and disadvantages of usage of mathematical model comparing with the trial-and-error way of development of new ice cream freezers. Following phenomena were taken into the account at mathematical model preparation:

- material properties, compressible fluid a non-Newtonian rheology;

- energy sources, heat transfer, scraping friction, crystallization and viscous dissipation;

- product formulation specifics, thermal conductivity, ice phase curve, specific heat. 
A mathematical model was implemented in $\mathrm{C}++$ and solved by MATLABSIMULINK simulation tool. Obtained results were the product temperature, mechanical dissipation and heat transfer rate. After experimental measurements, the results were shown in graphs like, compared experimental data and model prediction of heat transfer coefficient vs. product temperature. de Goede R. [13] in his thesis studied several aspects of crystallization of paraxylene inside the SSHE. His work focused on getting some useful tools to increase the purity of the final product and reach more efficient way of processing. His work is split into several chapters with a separate investigation as a brief description of common crystallization, incorporation of impurities in the crystal matrix, crystallization and its growth properties, heat transfer process and its properties, as the investigation on pilot plant.

Pyle et al. [14] in their work focused on the mathematical model to understand and describe the blade wear and present forces at blade tips including the consideration of fluid flow in corners and edges. The blade construction has an impact on blade wear, which is important from the point of possible excess of fouling on the heat transfer wall and significant blade fragments in the processed product. Based on their model they reported the initial rapid wear which goes to zero rate by time.

Zdravec et al. [15] investigated to determine the most advisable border between the rotating and stationary frame of reference in a case of Rushton turbine represented by a class of radial impellers as a model of impeller (Rushton agitated mixing vessel). Their selection of this impeller was based on some Laser Doppler Anemometry (LDA) measurements by different authors before. As a result they reported that by enlarging the dimension of rotation reference, the influence of numerical errors due to the interpolation inaccuracies in transferring the results between two domains.

Fitt et al. [16] investigated about the theoretical model for Newtonian fluids inside the cylindrical annulus with scraping blades and their configurations. The investigation was done for channeling, which is one of the undesired effects inside the SSHE. Fluid, product flow through SSHE without real heat treating. Pascual M. R. et al. [17] observed the flow pattern and heat distribution for SSHE in a case of crystallization. Their computational results completely supported the measured flow field and the picture obtained from the temperature distribution on the heat exchange surface.

Solano J. P. et al. [18] investigated an innovative self-cleaning shell and tube heat exchangers with fitted inner scraping rod by reciprocal movement. Pressure drop test were carried out in the hydro-dynamically developed region under isothermal process conditions. Fanning friction factor was determined from fluid mass flow rate and mean pressure drop measurements, while heat transfer experiments were carried out under uniform heat flux conditions and energy was added to the working fluid by Joule effect heating. Aloui F. et al. [19] presented an inverse method to determine the wall shear rate in SSHE using polarography technique. For experimental measurements they have used an industrial SSHE with high viscous of an isotherm Newtonian or non-Newtonian product, fluid (Emkarox HV45, PolyEthylene Glycol (PEG) 35000 and shear-thinning guar gum). Pascual, M. R. et al. [20] studied the SSHE for crystallization with turbulent flow and related solid particle behavior. The liquid flow was visualized by dye injection and particles monitored for two type of geometries. The goal of this work was to reach a good scraping of particles from heat transfer wall which adhere onto the heat transfer wall. Both simulation and experimental approach was carried out. 
Pascual M. R. et al. [21] performed large eddy simulations of the turbulent flow, at the Reynolds number of $5 \times 10^{4}$ for crystallizer geometry with main focus of the bottom region where the heat exchange surface was located. The simulation they validated by stereoscopic Particle Image Velocimetry (PIV) experiments. Blel W. et al. [22] investigated about clean-ability of inlet cell of the SSHE for optimization in order to reduce the hydro-dynamically dead zones. The main focus was done on new extended correlation previously presented on a simple system between the wall velocity gradient and the clean-ability. They have tested for contamination by spore-forming bacteria and biofilm. Using pulsating flow was reported as increasing the fluctuations and thereby reduces the residual contamination. Gandhi N., Prexa P. [23] prepared a CFD simulation and experimental measurements studying of effects like mass flow rate, blade design on a heat transfer and necessary power consumption of SSHE. The used product was milk, while cooling medium was water. The investigation was done for full blade design and partial - small blade design and their effect, difference on a heat transfer process and power consumption.

Arellano M. et al. [24] studied and compared their earlier experimental results for the sorbet crystallization, its nucleation, growth and breakage phenomena with two their mathematical model based on Population Balance Equation (PBE) and the coupled model of heat transfer and PBE with an empirical model of Residence Time Distribution (RTD). Results are shown in a series of graphs. They concluded that both approaches are very similar. Sun K. H. et al. [25] prepared a numerical 2D study of SSHE for non-Newtonian power law fluids, where they have been studied the effect on flow and heat transfer caused by blade design, material properties, shear and heat thinning. They have applied tangential and orthogonal blades with different gap at the fixation, shaft side. As a result they reported that for the shear thinning material the velocity profiles on the center line between two blades are flattened and position of center stagnation point shifted. Also noticed that for shear and heat thinning fluids, viscous dissipation is reduced close to the singularity corner, which caused the local heat fluxes and the average heat fluxes are reduced. Yataghene M. and Legrand J. [26] prepared a detailed 3D CFD model and analyses for their own geometrical solution. As a CFD tool was used Fluent 6.3 and for mesh model Gambit 2.2.3 The analyses were run for Newtonian fluid as pure Glycerin, for non-Newtonian fluid as $2 \mathrm{wt} \%$ Carboxymethyl cellulose (CMC) and 0.2 wt.\% Carbopol. Results, like temperature profiles are presented by several graphs. By increasing the rotating velocity in a case of non-Newtonian fluids the heat transfer was improved, while for pure Glycerin dramatically decreased. It was observed that viscous heating increases with rotating velocity. D'Addio L. et al. [27] provided a full 3D numerical solution by Fluent 6.2 for Non-Newtonian product, hazelnut paste. Numerical simulations were used to understand and observe the effect of blade rotational speed, paste flow rate or wall temperature on overall heat transfer coefficient. It was observed that heat transfer coefficient is higher for a case of cooling than for heating, and there is a more significant effect on it with increasing the rotational speed, as the mass flow rate. Rainieri S. et al. [28] presented a parametric, robust estimation of heat transfer correlation for $\mathrm{Nu}$ number on product, inner side of the SSHE, taking into the account that external heat transfer coefficient is unknown. The application to both synthetic and experimental data was provided. The parameter estimation was optimized for sensitivity 
and uncertainty. Both laminar and turbulent flow regimes were considered. Dehkordi K. S. et al. [29] prepared a numerical model to observe the influence of blade shapes and numbers, mass flow rate, shaft-scrapers revolution and the mechanism of applying flux. The relations are shown in several figures, e.g. outlet temperature respecting blade numbers or outlet fluid temperature on different stator material.

There are many further resource works including correlations for wide range of construction types and process conditions from various authors as Nikolajev L. N. [30] by dimensional analyses in a form:

$$
N u=c_{1} \operatorname{Re}_{a x}^{e_{1}} \operatorname{Pr}^{e_{2}}\left(\frac{N D_{s}}{v}\right)\left(\frac{P r_{f}}{P r_{w}}\right)^{e_{4}}\left(\frac{B}{D}\right)^{e_{5}}\left(\frac{L}{D}\right)^{e_{6}}\left(\frac{b}{D}\right)^{e_{7}}\left(\frac{d}{D}\right)^{e_{8}}
$$

where $R e_{\mathrm{ax}}, P r_{f}, P r_{w}$ are the characteristic non dimensional variables; $B, b$ are the characteristic dimensions of SSHE; $c_{1}$ is a constant and $e_{1-8}$ are the exponents of the correlation. Pálka R. [31], who prepared his experiments, presented in his dissertation thesis with the type of mutators and gave the correlations:

for water: $\quad N u=1.33 \operatorname{Re}_{\text {rot }}^{0.5} \operatorname{Pr}^{0.33} Z^{0.091}(7600<\operatorname{Re}<85000, \quad 2.2<\operatorname{Pr}<2.8, \quad 1<\mathrm{Z}<4$, $1.7<D / d<2.8,0.123<B / d<0.157$ )

and for glycerol: $N u=35 \operatorname{Re}_{\text {rot }}^{0.74} \operatorname{Pr}^{0.33} Z^{0.11}(140<\operatorname{Re}<2000,100<\operatorname{Pr}<230,2<Z<4$, $1.7<D / d<2.8,0.123<B / d<0.157)$.

Both given for a type of mutators with scrapes partially filling the area between the shaft and the heat transfer wall.

Devečka V. [32] who made his experimental measurement with the screw type of SSHE and gave his correlations in a form:

$$
N u=2.86 \operatorname{Re}_{\bmod }^{0.44} \operatorname{Pr}^{0.33}
$$

where $R e_{\text {mod }}$ is the modified Reynolds number according [32]. Kulatschinski A. [33] for the similar screw type of SSHE construction introduced his correlation in a form of:

$$
N u=21.67 \operatorname{Re}_{\text {rot }}^{0.44} \operatorname{Pr}^{0.33}\left(\frac{\eta}{\eta_{w}}\right)^{0.14}\left(\frac{D-d}{D}\right)^{0.35}
$$

Even of numerous available correlations, when there is a plan to thermally treat a new product with its specific thermodynamic properties or under the changed process conditions and modified votator's construction, the available correlations can lead to the wrong sizing of the new SSHE because of the mentioned facts in Ch. 1. 
In addition, it should be mentioned that dead zones inside the scraped surface heat exchangers should be avoided due to the quality loss high sensitive products during their thermal treatment. In Karches T. [34] can be seen an example solution for detection of dead zones by analyses of flow pattern. (in this case for channel flows). There are mentioned three different approaches to use CFD for detection of dead zones: Residence Time Distribution (RTD), Local Mean Age theory (LMA) and coherent structure concept with their advantages and disadvantages. In Krejčí T.et al. [35] can be seen a complex numerical solution for hydro-thermo-mechanical analyses of concrete structures. The work is focused on control of hydration heat evolution and moisture content, because of high influence of the lifecycle of structure. The used tool for analyses was the open source program SIFEL.

\section{Experimental measurements by horizontal SSHE with a new design of votator}

The goal of the experimental measurements was to build up a new correlation for Nusselt number in a form of $N u=f\left(\operatorname{Re}, \operatorname{Pr}, \eta_{f} \eta_{w}\right)$ for the new proposed construction of the votator, mutator and confront the results with ones from the numerical analyses. The exponent of the $\operatorname{Pr}$ number and viscosity was taken from other works. For experimental measurements, two horizontal SSHE's were built in series as a unit (see Fig. 1a). At the first stage the product was heated by vapor to achieve a constant wall temperature, at second stage was cooled by cold water from the water-supply connection. Thermocouples were released alongside the heat transfer tube, wall in a distances $\mathrm{L}=125.375$ (2x-one rotated by $120 \mathrm{deg}$.), $625.8 \mathrm{~mm}$, at all inlets-outlets and at inlet and in the middle of the $\mathrm{HE}$ in radial directions between the heat transfer wall and shaft as shown on Fig. $1 b$.
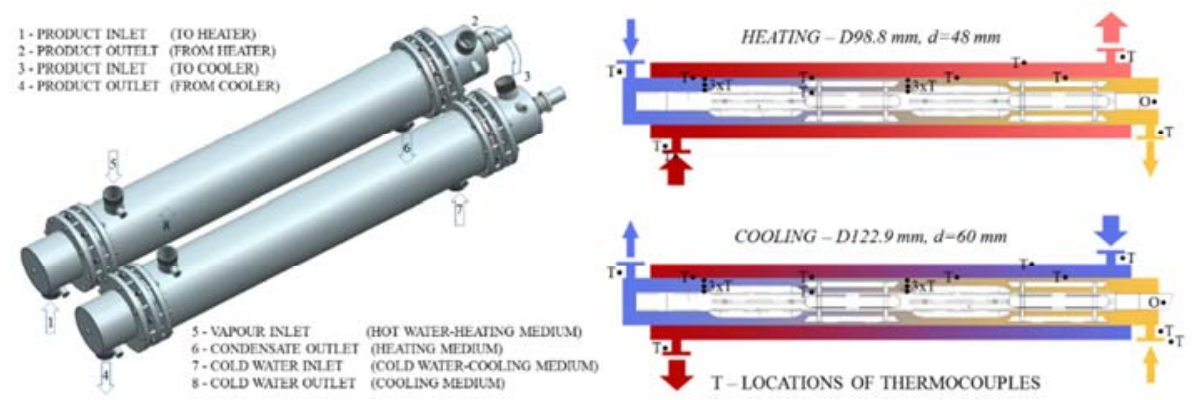

Fig. 1. a) Two horizontal scraped surface heat exchangers connected in series;

b) Scheme of the flow direction and heat treat process and positions of thermocouples

The product was fed by gear-pump in a closed circuit. The internal votator construction was a new own design in two executions, with and without rectifiers on the rotating shaft, see Fig. 2a. In Fig. $2 b$ the temperature course can be seen along the vertical cross section at Center Line (CL) through the presented horizontal SSHE including the votator construction with rectifiers on the rotating shaft. Water was used 
as a product (validate the results from numerical solutions). Applied mass flow and rotary velocity as follows: $\mathrm{m}=250,500,750$ and $1000 \mathrm{kgh}^{-1} ; \mathrm{rpm}=20,30,(45), 60,90$ $\min ^{-1}$. The measured values were recorded regularly at every 5 seconds for all process conditions and taken for data evaluation only after reached steady state conditions.

Processing all the recorded result from experimental measurements the correlation was received in a form of:

$$
N u=5.9 \operatorname{Re}_{r o t}^{0.35} \operatorname{Pr}^{0.33}\left(\frac{\eta}{\eta_{w}}\right)^{0.14}
$$

This correlation is a general equation for a calculation of $N u$ number for heating, cooling process and for both type of mutator's construction taken into the account. The following correlation is the one for getting the $N u$ number for only a case of heating for both type of votator $N u=6.5 \operatorname{Re}_{\text {rot }}^{0.34} \operatorname{Pr}^{0.33}$ and in case of cooling: $N u=10.1$ Re $_{\text {rot }}^{0.304}$, where $_{w}$ means at wall temperature.

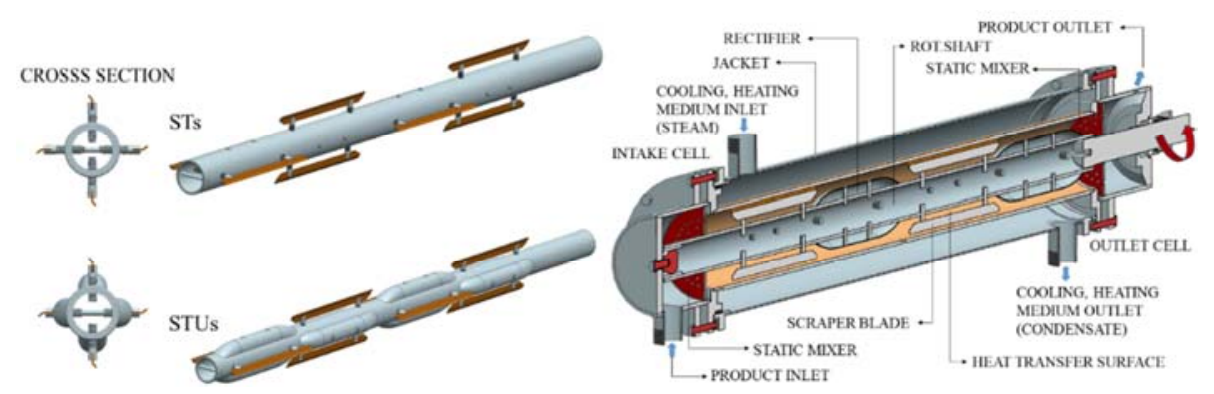

Fig. 2. a) Two execution of votators, without and with rectifiers on the rotating shaft, $\mathrm{d}=60 \mathrm{~mm}$ for cooling, $\mathrm{d}=48 \mathrm{~mm}$ for heating; $b$ ) Vertical cross section at CL through the horizontal SSHE, $D_{\text {jacket-in }}=172 \mathrm{~mm}, D_{\text {heat-transfer-in }}=98.8 / 122.9 \mathrm{~mm}, d_{\text {shaft-out }}=48 / 60 \mathrm{~mm}$

The prediction that results by using the mutators with built in rectifiers will be more efficient, was not confirmed fully by using the water as product. This can be explained by good radial mixing with both executions of votators in a case of water. On the other hand, the higher, even very big difference in efficiency can be predicted surely for high viscous, non-Newtonian products (already seen from the preliminary numerical solutions for honey, ketchup, chocolate cream).

\section{Numerical analyses of the horizontal SSHE}

In parallel with the practical measurement the numerical model was prepared and then for numerical analyses the applied process and boundary conditions from measurements were adopted as much as possible. As the full numerical model requires 
too many nodes, taking into account the available computer capacity and necessary time for run, the simplification of it had to be considered.

The chosen simplified model (see Fig. 3a, Fig. 3b) with taking only the area between the heat transfer tube, wall and the shaft. This simplification is quite respectable, mainly for a stage of cooling where expected constant heat transfer wall temperature in numerical model can significantly differ from the real case (higher deviation of results comparing the practical measurement, the simplification should be revaluated).

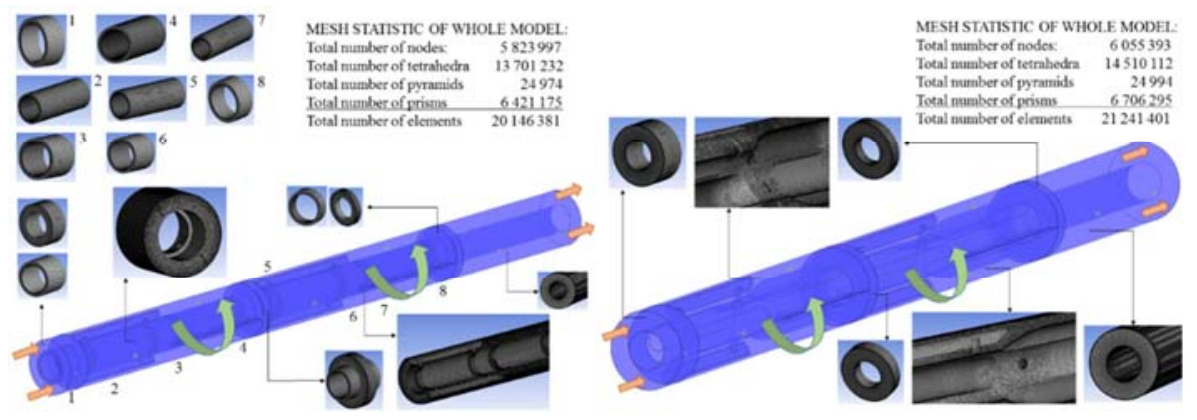

Fig. 3. Simplified numerical models for a) STs type of mutator and b) STUs type of mutator

There are some other deviations by simplification which can lead to higher differences between obtained results. There are for instance, the inlet surface where the equally released mass flow was considered, but in real case this differ significantly, than the missing inlet-outlet cells, which has an effect on the flow character and can cause a difference as well and some others. For getting better overview in later stage, analyses with inlet and outlet cells will be provided (because of pressure loss information and characteristic of flow, which will be reported by different paper).

The simplified model was built from stationary and rotary domains according the real process conditions. This takes into the account the rotary motion of blades and rectifiers. In case of rotating shaft with scraper blades and rectifiers on it (STUs type), the full cross section (in a length of blades) was rotary, while at rotating shaft with scraper blades but without rectifiers on it (STs type), only the affected part. The border of rotary and stationary domain was set up on $2 \mathrm{~mm}$ from lower edge of blades (in radial direction). This is a value, which should be checked for different offsets and the results should be compared, to be sure with specified value (due to the rotary motion effect of blades on product's flow). To minimize the effect at outlet, a $300 \mathrm{~mm}$ extra length of pipe segment was specified. The specified stationary domains at inlet, in the middle and outlet were used because the built-up plant had a thermocouples added in these positions and the aim was following the situation from experimental plant on numerical model as much as possible. The real construction if SSHE's are designed without these 'areas', except the situation where it belongs to the inlet or outlet cell.

The initial, boundary conditions as follows: inlet temperature from the experimental measurement, the heat transfer wall temperature specified as a constant value, which 
was calculated from the measured values alongside the heat transfer wall (arithmetic average), on inlet surface the equally released mass flow, reference pressure 1 bar(a), product outlet specified as opening. Applied turbulence model was the Shear Stress Transport model (SST). The initialization turbulence was 5\% (specified as medium according CFX tool, for a case when it is not know in advance). The analyses were provided under the steady state conditions.

After provided analyses the temperatures were taken into the chart from the simplified model from the inlet through the SSHE at $20 \mathrm{~mm}$ distances in cross sections perpendicular on axis of the SSHE. The temperatures taken from numerical model are the average values in section (shows difference with experimental values, which are local temperatures at applied positions). The inlet and outlet temperatures from numerical model are taken at the inlet and outlet surface also as an average value, while the measured values are taken at the inlet, outlet position exactly where the thermocouples are located.

There are several results, which can be obtained from the numerical analyses for valuation and better understanding the overall process (e.g. velocity profiles, temperature fields, local vortices, pressure losses, etc.), but this paper focusing only the temperature field alongside the heat exchanger and the overall temperature change. In Fig. $4 a$, Fig. $4 b$ some obtained results $\left(\mathrm{m}=1000 \mathrm{kgh}^{-1}, \mathrm{rpm}=90 \mathrm{~min}^{-1}\right.$, heating case) from numerical analyses can be seen, which are quite important to understand the process conditions and temperature field development.

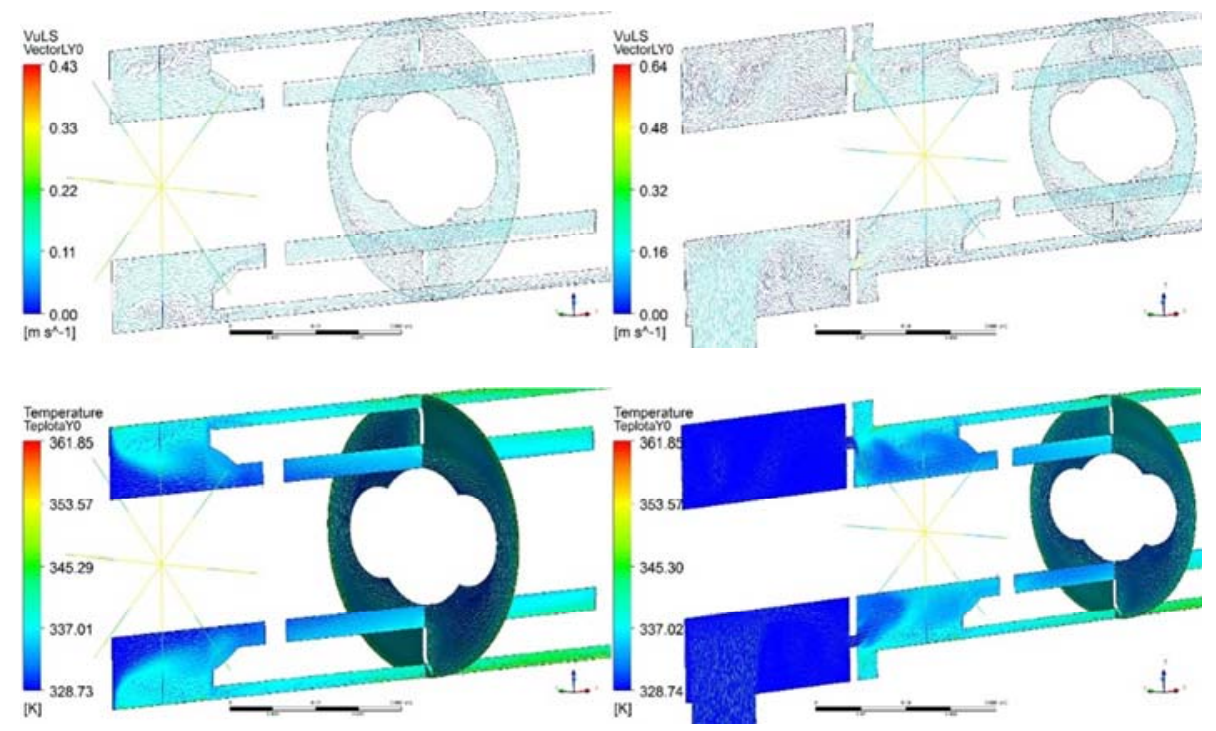

Fig. 4. Axial velocity ( $V x z$ ) vector and temperature distribution in a CL section for simplified model a) without inlet cell, and b) incl. the inlet cell 


\section{Results}

After all results were processed and arranged into the graphs and charts, it can be seen that the numerical solutions are giving a good approximation, even though the simplified model was applied. Most results showed only $6 \%$ of discrepancy between the measured and calculated data. The rest, where the difference is higher (still below $11 \%$ ) can be accepted as adequate, because of the reported simplification for numerical model mentioned in Ch. 4. The difference between the numerical and experimental data was below $3 \%$ in case of using more detailed numerical model of the heat exchanger (inlet and outlet cell included).

There are several reasons of those higher differences which could be found behind like the used turbulence model (these are all based on some prediction, which leads to some difference). Another significant effect on differences (but this can be due to the simplification as well), the effect of heat conduction from the process (heat transfer wall) to all the construction parts of the SSHE. This was taken at numerical analyses on the shaft as adiabatic wall, and in a case of included inlet/outlet cells those had adiabatic walls as well. These facts can just confirm that usage of detailed, full numerical model solution will be very close to real process conditions.

The results confirmed the written assumption in $\mathrm{Ch}$. 1 that by numerical analyses can be reduced the costs of SSHE development or improvement for any process conditions. There is no necessary to manufacture a scale plant for all new proposed construction to get the results for valuation, just for the ones where the numerical solutions will give the best assumes, results (this is a huge benefit of the available CFD tools)

Hereby below in Fig. 5 the processed graph and charts of obtained results is shown. Here the temperature rise alongside the horizontal SSHE in a case of simplified model with and without applied inlet/outlet cell can be seen, as the measured values from the measurement. The immediate temperature rise just after the inlet can be explained by means of local turbulence caused by rotary motion of scraper blades (see Fig. $4 a$, Fig. 4b). This effect is more significant if rotary velocity increased. On the other hand, it can be seen that in a case of applied inlet cell for numerical solution (and in real process conditions) the effect is partly balanced (e.g. caused by applied static mixer). The disadvantage of those static mixers is present due to the caused pressure drop (overall energy consumption) and the necessary cleaning process of them.

The difference between the measured and simulated results for STUs and STs type of votators for process conditions, heating and cooling are not higher than $6.5 \%$ for all cases. From the chart can be seen that the difference of the temperatures (measured and calculated) are in some cases higher in certain distance from the inlet, but closer at the end. This is due to the taken average temperature in cross sections from the numerical analyses, while in the practical measurement the thermocouples are measuring the local temperatures. During the measurements were observed that the position of thermocouples had an effect on obtained temperatures. The best performance was received when the thermocouples were on the side of the case. When orientation was against the axial flow or just behind the case, the results shows higher discrepancy. This could be by local turbulence around the case or by the heat conduction of the case from the heat transfer tube/wall as well. 


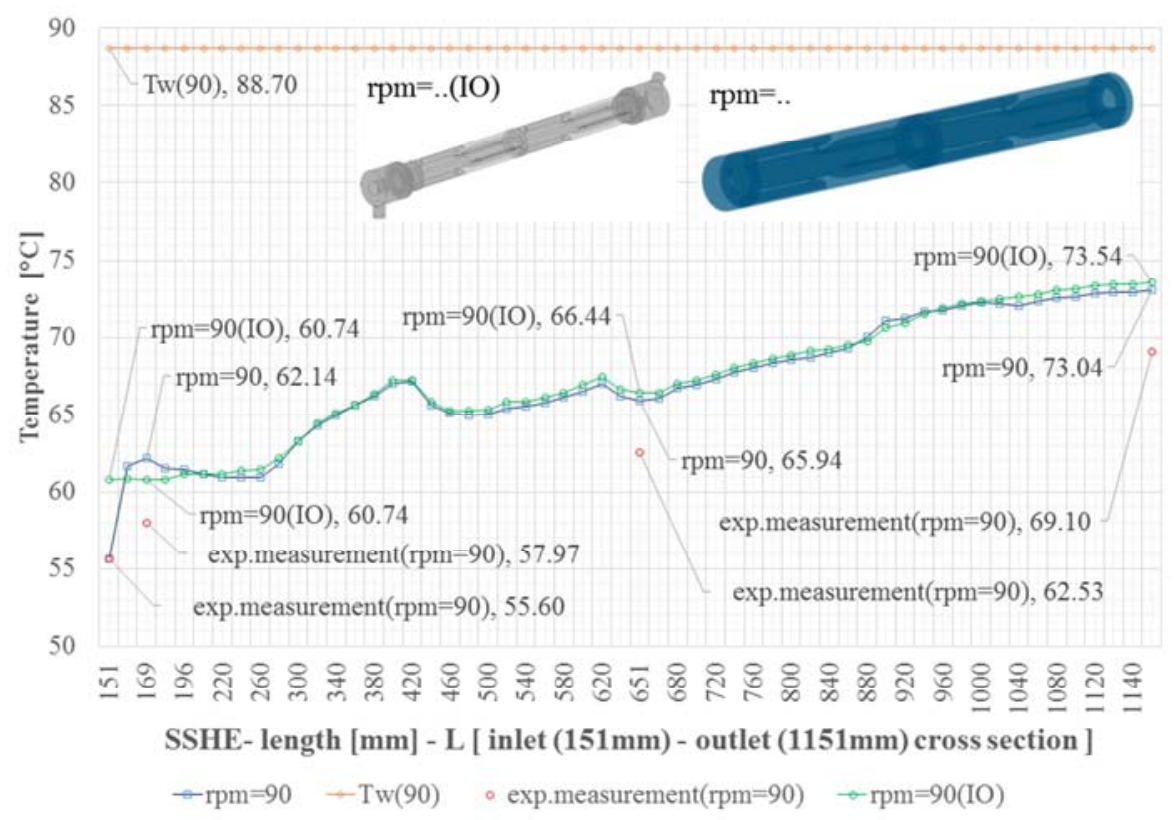

Fig. 5. Measured and numerical results. (heating, $\mathrm{m}=1000 \mathrm{kgs}^{-1}, \mathrm{rpm}=90 \mathrm{~min}^{-1}$ )

\section{Conclusion}

Based on the results from the measurement and numerical analyses can be stated that the usage of CFD tools for development or design of new type of SSHE's, or their development for different type of treated product has a strong base and can lead to the economic benefits. The results were validated successfully. During the process of these measurements and numerical analyses more construction types of votators were designed and developed. For those new type of constructions numerous numerical analyses were already provided to evaluate the temperature and velocity field. Some of the results from these numerical solutions were already published. The measurements will be future plans for those new constructions, in cooperation with possible consumer, manufacturer of SSHE's. The conclusion of above prepared work gives a good base to continue certify the same for usage of high viscous non-Newtonian products like caramel, mineral oils, puddings, ground meat, dyes or any specific, sensitive products.

\section{References}

[1] Huggins F. E. Jr. Effect of scrapers on heating, cooling and mixing, Ind. Eng. Chem, Vol. 23, No. 7, 1931. pp. 749-753.

[2] Latinen G. A. Discussion of the paper: Correlation of scraped film heat transfer in the votator by Skelland A. H. Chem. Eng. Sci, Vol. 9, 1959. pp. 263-266. 
[3] Harriot P. Heat transfer in scraped-surface exchangers, Chem. Eng. Progr. Symp. Ser, Vol. 54, 1959, pp. 197-139.

[4] Skelland A. H. P. Correlation of scraped-film heat transfer in the votator, Chem. Eng. Sci, Vol. 7, 1958, pp. 166-175.

[5] Weisser H. Untersuchungen zum Wärmeübergang im Kratzkühler, Karlsruhe Universität, Germany, 1972.

[6] Härröd M. Flow patterns, mixing effects and heat transfer in scraped heat exchangers, Dept. of Food Science, Chalmers University of Technology, Göteborg, Sweden and SIK, The Sweden Institute for Food Research, 1988.

[7] Härröd M. Methods to distinguish between laminar and vortical flow in scraped surface heat exchangers, J. Food Process Eng, Vol. 13, No. 1, 1990, pp. 39-57.

[8] Tero T. Suspension melt crystallization in tubular and scraped surface heat exchangers, Mathematisch-Naturwissenschaftlich-Technischen Fakultät der Martin-Luther-Universität Halle-Wittenberg, 2004.

[9] Pascal M. R., Ravalet F., Delfos R., Witkamp G. J. Measurement of flow field and wall temperature distribution in a scraped surface heat exchanger crystallizer, in 5th Europian Thermal-Sciences Conference, Eindhoven, The Netherlands, 18-22 May 2008, Paper 2.

[10] Wilson S. K., Duffy B. R., Lee M. E. M. A mathematical model of fluid flow in a scrapedsurface heat exchanger, J. Eng. Math, Vol. 57, No. 4, 2007, pp. 381-405.

[11] Trommelen A. M. Physical aspects of scraped surface heat exchangers, Delft University of Technology, 1970.

[12] Bongers P. M. M. A heat transfer model of a scraped surface heat exchanger for ice cream, in 16th European Symposium on Computer Aided Process Engineering and 9th International Symposium on Process Systems Engineering, Garmisch-Partenkirchen, Germany, 9-13 July 2006, Computer Aided Chem. Eng, Vol. 21, 2006, pp. 539-544.

[13] Degoede R. Crystallization of paraxylene with scraped surface heat exchangers, Technische University Delft (Netherlands), 1988.

[14] Pyle D. L., Sun K. H., Lee M. E. M., Please C. P., Fitt A. D., Wilson S. K., Duffy B. R., Hall-Taylor N. Effective scraping in a scraped surface heat exchanger: some fluid flow analysis, International Congress on Engineering and Food, Montpellier, France, 7-11 March 2004.

[15] Zdravec M., Basic S., Hribersek M. The influence of rotating domain size in a rotating frame of reference approach for simulation of rotating impeller in a mixing vessel, J. Eng. Sci. Technol, Vol. 2, No. 2, 2007, pp. 126-138.

[16] Fitt A. D., Lee M. E. M., Please C. P. Analysis of heat flow and 'channeling' in a scrapedsurface heat exchanger, J. Eng. Math, Vol. 57, No. 4, 2007, pp. 407-422.

[17] Pascual M. R., Ravelet, F., Delfos R., Derksen, J. J., Witkamp, G. J. Computational fluid dynamics and measurement of flow field and wall temperature distribution in a scraped heat exchanger crystallizer, in Proceedings of the 17th International Symposium on Industrial Crystallization, Maastricht, The Netherlands, 14-17 September 2008, pp. 1889-1896.

[18] Solano J. P., García A., Vicente P. G., Viedma A. Performance evaluation of a zero-fouling reciprocating scraped-surface heat exchanger, Heat Transf. Eng, Vol. 32, No. 3-4, 2011, pp. 331-338.

[19] Aloui F., Rehimi F., Dumont E., Legrand J. Inverse method applied for the determination of the wall shear rate in a scraped surface heat exchanger using the electrochemical technique, Int. J. Electrochem. Sci, No. 3, 2008, pp. 676-690.

[20] Pascual M. R., Derksen J. J., Van Rosmalen G. M., Witkamp G. J. Flow and particle motion in scraped heat exchanger crystallizers, Chem. Eng. Sci, Vol. 64, No. 24, 2009, pp. 5153-5161. 
[21] Pascual M. R., Ravelete F., Delfos R., Derksen J. J., Witkamp G. J. Large eddy simulations and stereoscopic particle image velocimetry measurements in a scraped heat exchanger crystallizer geometry, Chem. Eng. Sci, Vol. 64, No. 9, 2009, pp. 2127-2135.

[22] Blel W., Legentilhomme P., Benezech T., Fayolle F. Cleanabilty study of a scraped surface heat exchanger, Food Bioprodducts Processing, Vol. 91, No. 2, 2013, pp. 95-102.

[23] Nilay G., Prexa P. Thermal analysis of scraped surface heat exchanger used in food industries, Int. J. Innov. Sci. Eng. Technol, Vol. 2, No. 5, 2015, pp. 622-627.

[24] Arellano M., Benkhelifa H., Alvarez G., Flick D. Coupling population balance and residence time distribution for the ice crystallization modeling in a scraped surface heat exchanger, Chem. Eng. Sci, Vol. 102, 2013, pp. 502-513.

[25] Sun K. H., Pyle D. L., Fitt A. D., Please C. P., Baines M. J., Hall-Taylor N. Numerical study of 2D heat transfer in a scraped surface heat exchanger, Computers \& Fluids, Vol. 33, No. 5-6, 2004, pp. 869-880.

[26] Yataghene M., Legrand J. A 3D-CFD model thermal analyses within a scraped surface heat exchanger, Computers \& Fluids, Vol. 71, 2013, pp. 380-399.

[27] D'Addio L., Carotenuto C., Di Natale F., Nigro R. Heating and cooling of hazelnut paste in alternate blades scraped surface heat exchangers, J. of Food Eng, Vol. 115, No. 2, 2013, pp. 182-189.

[28] Rainieri S., Bozzoli F., Cattani L., Vocale P. Parameter estimation applied to heat transfer characterization of scraped surface heat exchangers for food applications, J. of Food Eng, Vol. 125, 2014, pp. 147-156.

[29] Dehkordi K. S., Fazilati M. A., Hajatzadeh A. Surface scraped heat exchanger for cooling Newtonian fluids and enhancing its heat transfer characteristic, a review and numerical approach, Applied Thermal Eng, Vol. 87, 2015, pp. 56-65.

[30] Nikolajev L. N. Allgemeine Gleichung für den Wärmeübergang in kontinuierlich arbeitenden, röhrenförmigen kratz apparaten, Pitschev Technol., Vol. 3, 1965, pp. 127-129.

[31] Pálka R. The kinetics of heat transfer at the heat transfer surface by mechanically aided boundary layer, (in Slovak) Slovenská Technická Univerzita v Bratislave, Strojnícka Fakulta, 1999.

[32] Devečka V. Contribution to the problem of the kinetics of heat transfer on the rotary heat transfer surfaces, (in Slovak) Slovenská Technická Univerzita v Bratislave, Strojnícká Fakulta (SjF STU), 1994.

[33] Kulatschinski A. Wärmeaustausch in horizontalen, zylindrischen Wärmeaustauschern, Molochn. Prom, Vol. 26, No. 2, 1962, pp. 11-15.

[34] Karches T. Detection of dead-zones with analysis of flow pattern in open channel flow, Pollack Periodica, Vol. 7, No. 2, 2012, pp. 139-146.

[35] Krejčí T., Koudelka T., Kruis J. Numerical modeling of coupled hydro-thermo-mechanical behavior of concrete structures, Pollack Periodica, Vol. 10, No. 1, 2012, pp. 19-30. 